\title{
Droplet Heating and Evaporation: Recent Developments of Simple Models of Complex Processes
}

\author{
Sergei S. Sazhin \\ Advanced Engineering Centre \\ School of Computing, Engineering and Mathematics \\ University of Brighton \\ Brighton BN2 4GJ, UK \\ S.Sazhin@brighton.ac.uk
}

\section{Extended Abstract}

The most recent and important developments in the modelling of heating and evaporation of mono- and multicomponent droplets since the publication of the author's monograph [1] and review paper [2] are reviewed. In contrast to the models used in most engineering applications, the effects of temperature and species mass fraction gradients within spherical droplets are considered based on the analytical solution to the one-dimensional heat transfer and species diffusion equations, assuming that the heating process is also spherically symmetrical. It is shown that this approach is particularly useful for practical applications in CFD codes. The models were implemented into the ANSYS Fluent CFD code using User-Defined Functions (UDF). The predictions of this code, inclusive of the new models, were verified against the results predicted by the in-house research code [3]. In the case of hydrocarbon fuels with large numbers of components a multi-dimensional quasi-discrete model has been developed. In this model, the contributions of individual components are replaced by the contributions of groups of components with close transport and thermodynamic properties, called quasi-components [2]. A new, relatively simple, approach to the modelling of heating and evaporation of suspended droplets that can be applied to water sprays for fire suppression [4], and the modelling of heating and evaporation of multi-component liquid films are discussed [5]. Simplified approaches to the modelling of micro-explosions for automotive applications are presented. These approaches are based on analytical solutions to the heat conduction equation in a composite droplet with Dirichlet and Robin boundary conditions at the droplet surface, and continuity conditions at the fuel-water interface [6,7]. In the latter model, the time instant when the temperature at the water-fuel interface is equal to the water nucleation temperature is associated with the start of puffing/micro-explosion.

\section{References}

[1] S.S. Sazhin, Droplets and Sprays. Springer, 2014.

[2] S.S. Sazhin, "Modelling of fuel droplet heating and evaporation: recent results and unsolved problems," Fuel, vol. 196, pp. 69-101, 2014.

[3] O. Rybdylova, L. Poulton, M. Al Qubeissi, A.E. Elwardany, C. Crua, T. Khan, S.S. Sazhin, "A model for multicomponent droplet heating and evaporation and its implementation into ANSYS Fluent," Int. Comm. Heat and Mass Transfer, vol. 90, pp. 29-33, 2018.

[4] P.A. Strizhak, R.S. Volkov, G. Castanet, F. Lemoine, O. Rybdylova, S.S. Sazhin, "Heating and evaporation of suspended water droplets: experimental studies and modelling," Int. J. Heat and Mass Transfer, vol. 127, pp. 92-106, 2018

[5] S.S. Sazhin, O. Rybdylova, C. Crua, "A mathematical model for heating and evaporation of a multi-component liquid film,” Int. J. Heat and Mass Transfer, vol. 117, pp. 252-260, 2018.

[6] S.S. Sazhin, O. Rybdylova, C. Crua, M. Heikal, M.A. Ismael, Z. Nissar, A.R.B.A. Aziz, "A simple model for puffing/micro-explosions in water-fuel emulsion droplets," Int. J. Heat and Mass Transfer, vol. 131, pp. 815-821, 2019.

[7] S.S. Sazhin, T. Bar-Kohany, Z. Nissar, D. Antonov, P.A. Strizhak, O.D. Rybdylova, "A new approach to modelling micro-explosions in composite droplets," Int. J. Heat and Mass Transfer, vol. 131, 120238, 2020. 